\title{
Statistical Analysis of Rainfall Trend for Volta Region in Ghana
}

\author{
M. Nyatuame, V. Owusu-Gyimah, and F. Ampiaw \\ Agricultural Engineering Department, Ho Polytechnic, P.O. Box 217, Volta Region, Ghana \\ Correspondence should be addressed to M. Nyatuame; doga_nyatuame@yahoo.com
}

Received 27 June 2014; Accepted 6 September 2014; Published 19 October 2014

Academic Editor: Panagiotis Nastos

Copyright (C) 2014 M. Nyatuame et al. This is an open access article distributed under the Creative Commons Attribution License, which permits unrestricted use, distribution, and reproduction in any medium, provided the original work is properly cited.

\begin{abstract}
Climate change is global in nature, but potential changes are not expected to be globally uniform; rather, there may be dramatic regional differences. Considerable effort should be invested to understand climate change at the regional level. The study was conducted to establish the rainfall trends in Volta Region and also to provide the evidence of climate change by analyzing available rainfall record for 30-year period of 1981 to 2011. Records of monthly and yearly rainfall were obtained from the headquarters of Ghana Meteorological Department, Accra, for analysis. The region was grouped into three zones characteristic of the whole country, namely, coastal zone, middle zone, and northern zone, respectively. Graphs were constructed to illustrate the changing trends within the months and years of the zones. Statistical analysis (i.e., LSD, ANOVA) was performed to assess any significant difference among the three zones and within the months and years under study. Significant differences were observed among the three zones. Northern zone recorded the highest precipitation followed by the middle zone and lastly the coastal zone. However the rainfall trends within the aforementioned zones were oscillatory. The highest annual mean rainfall was $202.6 \mathrm{~mm}$ and the lowest was $29.9 \mathrm{~mm}$. Linear regression analysis revealed upward and downward trend in the data in some months and years in the mentioned zones but statistically insignificant.
\end{abstract}

\section{Introduction}

Water is one of our most valuable natural resources and vital to all forms of life. Water is also used for transportation, is source of power, and serves many other useful purposes for domestic consumption, agriculture, and industry. The main important source of water in any area is rain. The amount or availability of water for various purposes is very much depending upon the amount of precipitation in that particular area. Excess or extended absence of rainfall will cause flooding and drought, respectively. Adler et al. [1] stated that precipitation information is essential for understanding the hydrologic balance on a global scale and for understanding the complex interactions among the components within the hydrologic cycle.

The availability of adequate freshwater of appropriate quality has become a limiting factor for development worldwide [2]. In arid and semiarid regions of the world, water scarcity and low per capita water allocation were always a dominant challenge. The situation has further exacerbated due to increase in population and the associated expansion of urbanization and economic activities, all of which demand more water and thus impose a tremendous pressure on the inadequate water resources.

Rainfall is the meteorological phenomenon that has the greatest impact on human activities and the most important environmental factor limiting the development of the semiarid regions [3]. Understanding rainfall variability is essential to optimally manage the scarce water resources that are under continuous stress due to the increasing water demands, increase in population, and the economic development [4].

There are many aspects of water resources management including the optimal water allocation, quality assessment and preservation, and prediction of future water demands to strategize water utilization, planning, and decision making. As a preliminary step, these management aspects and others necessitate the characterization of the water sources in the area of interest. One of the established methods to carry out this assessment is through the statistical analysis of the spatial and temporal variability of rainfall. In regions that have heavy agricultural areas and undergo dense activities, water availability and shortage challenges are further exacerbated. 
In Ghana, many watersheds are under extreme stresses due to the climate changes and drought conditions that influence water availability in a negative manner when considering the increasing need to boost up the agricultural production rate [5].

While climate change is global in nature, potential changes are not expected to be globally uniform; rather, there may be dramatic regional differences. Considerable effort should be invested to understand climate change at the regional level. Volta Region is one of the ten regions in Ghana (Figure 1), and it is said to be a microcosm of Ghana. That is to say all the six ecological zones in Ghana are represented in Volta Region (Figure 2).

This situation has compelled the motivation for assessing the magnitude and variability of rainfall for Volta Region. Statistical analysis of rainfall records for long periods is essential to provide information about rainfall variability and to better manage the rain fed agricultural activities such that the impact of climate change as well as changes in land use can be realistically assessed.

This paper carries out a statistical analysis of the longterm rainfall data for the Volta Region. The major objective of this work is to statistically analyze the temporal variation in annual and monthly rainfall data of Volta Region. This analysis is essential to provide input data for a management system and to enable the development of optimal water allocation policies and management strategies to bridge the gap between water needs and obtainable water supply under possible drought conditions. On an annual scale, the analysis will help in the evaluation of the total water budget of the water resources in the area. Monthly rainfall analysis can be used in the determination of the crop water requirements. The paper is organized as follows. Description of Volta Region is presented followed by the annual and monthly rainfall statistical analysis. Time series of annual and monthly rainfall data were studied and annual trends were extracted and conclusions are furnished.

The Volta Region is located along the southern half of the eastern border of Ghana, which it shares with the Republic of Togo. Greater Accra, Eastern, and Brong Ahafo regions share boundaries with it on the west, on the north by the Northern Region, and on the south by the Gulf of Guinea. The region occupies an area of about 20,570 square kilometres or 8.6 per cent of the total land area of Ghana [6].

The region has a length of about 500 kilometres, stretching from the south to the north. It encompasses most of the vegetation zones found in the country, that is, the coastal grassland and mangrove swamps, replete with sandy beaches, the Guinea savannah through moist semideciduous forests in the central highland areas to the undulating Sahel-savannah, and the mountainous wooded savannah in the north [6].

As in all other parts of the country, the Volta Region has a tropical climate, characterised by moderate temperatures, $21-32^{\circ}$ Celsius $\left(70-90^{\circ} \mathrm{F}\right)$, for most of the year. The region has two rainfall regimes in the year; the first is from March to July and the second is from mid-August to October. Rainfall figures, which vary greatly throughout the region, are highest in the central highland areas and in the forest zone; they are lowest in the Sahel-savannah zone in the north of the region.

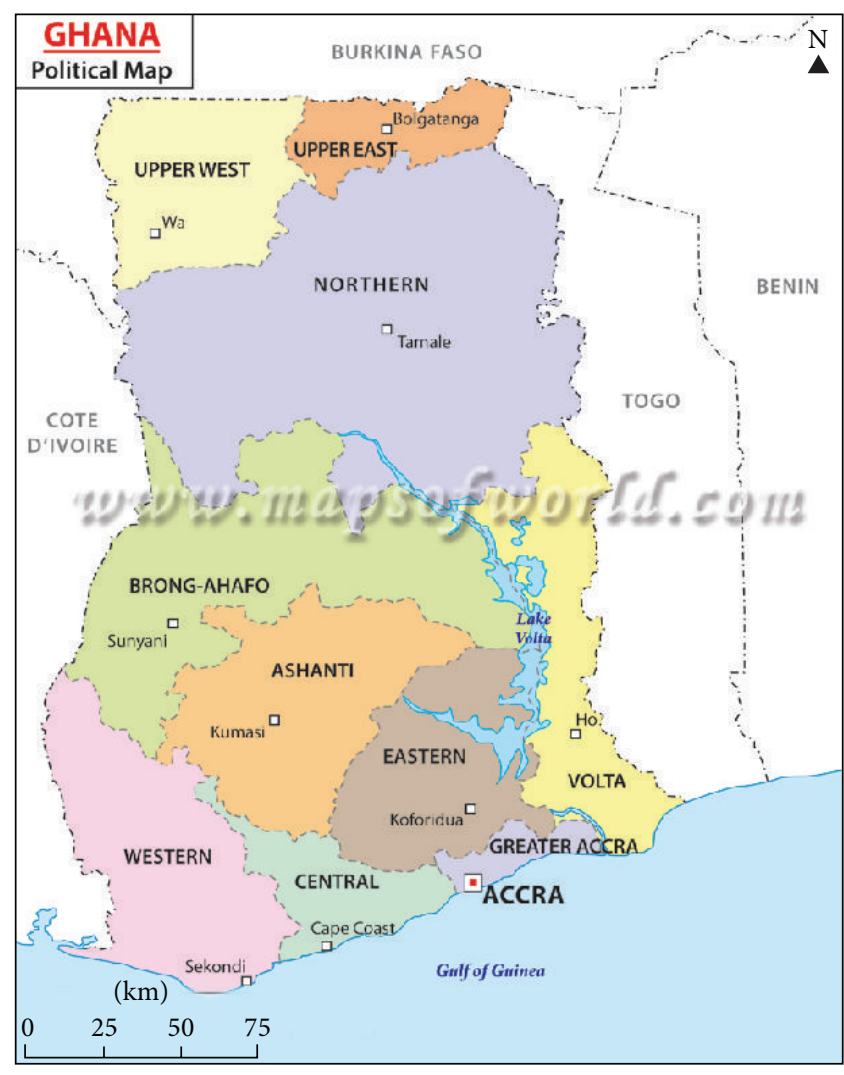

-..- International boundary

$\square$ National capital

Regional capital

Figure 1: Map of Ghana.

The maximum average annual rainfall figure is $2,103 \mathrm{~mm}$ and $1,168 \mathrm{~mm}$, minimum. More than half of the land area of the region falls within the Volta River Basin, with the Volta Lake draining a substantial portion of the region [6]. The region's mountains form part of the Togo Range, which stretches from parts of the Ashanti and Eastern Regions into the Republic of Togo. The highest mountain in Ghana, Mount Afadjato (Avadzeto), located in the Hohoe District, is part of this range. This mountain, together with several picturesque physical features such as the Wli waterfalls, near Mountain Gemi (Amedzofe), and the monkey sanctuary in Tafi (Hohoe district) are some of the region's tourist attractions [6].

\section{Materials and Methods}

Monthly rainfall data were obtained from the Ghana Meteorological Department on Volta Region. Volta Region was used in the study because it represents the entire climatic scope of Ghana. The six ecological zones in Ghana are represented in the Volta Region, hence the saying that Volta Region is the microcosm of Ghana. The data obtained cover the period of 1981 to 2011 and the Volta Region was grouped into three zones, namely, coastal, middle, and northern zones, respectively. Statistical analyses were performed to assess any significant difference among the three zones and within the months and years under study on the data and graphs 


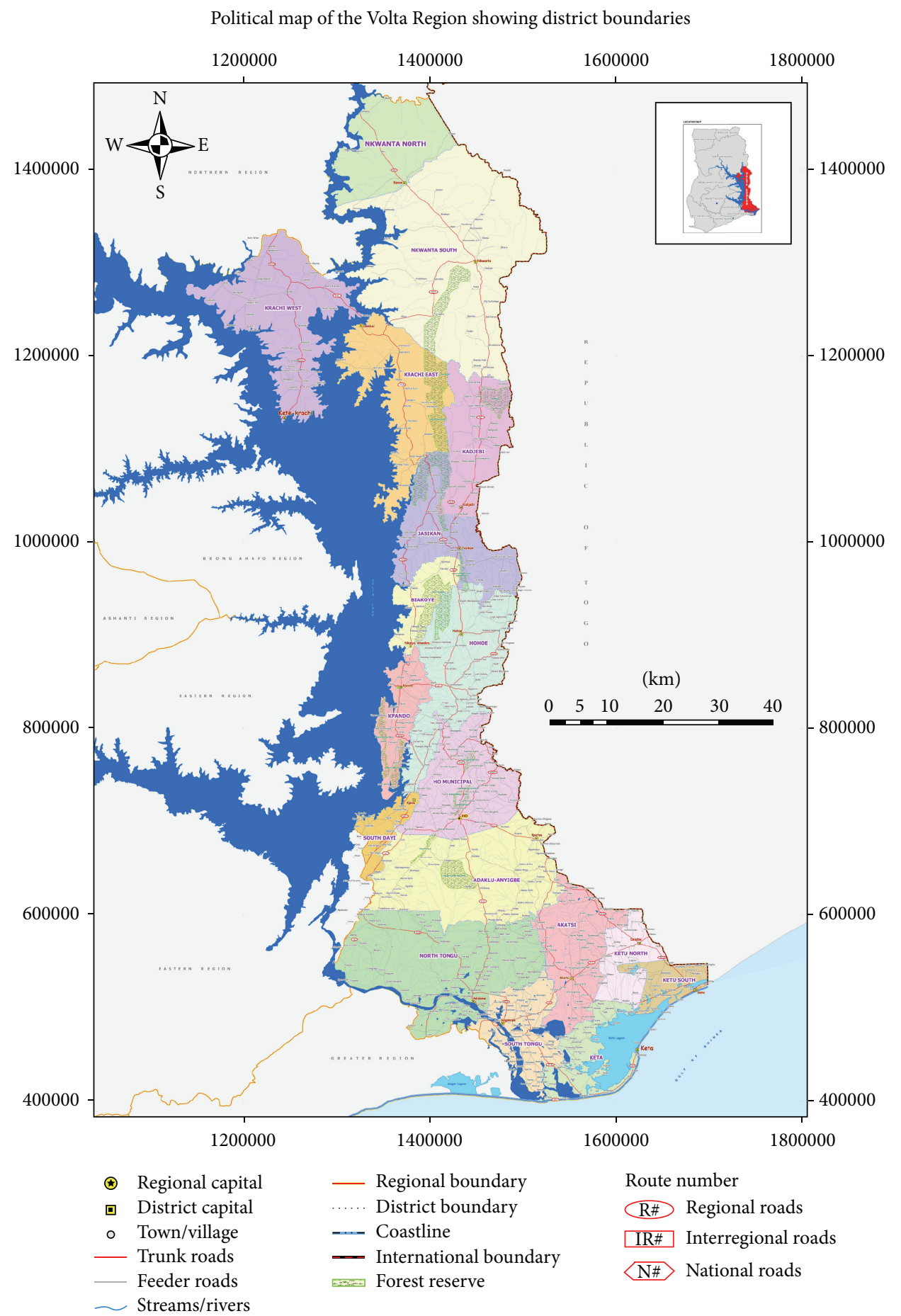

FIgURE 2: Map of Volta Region.

were constructed to illustrate the changing trends within the months and the years for the period. The statistical analysis was used to determine the measure of central tendency (mean, range, etc.) and dispersion (S.D., CV, etc.). For identifying the trend in the rainfall data, the statistical analysis of linear regression was used.

Linear regression is one of the simplest methods to calculate the trend of data in time series. The equation of linear regression line is given by $Y=a+b X$, where $X$ is the independent variable and $Y$ is the dependent variable. The slope line is $b$ and $a$ is the intercept (value of $Y$ when $X=0$ ). The slope of regression describes the trend whether positive or negative. In this study dependent variable $Y$ is rainfall and independent variable $X$ is year. Linear regression requires the assumption of normal distribution. In this study, the null hypothesis is that the slope of the line is zero or 
there is no trend in the data. The significance of the slope is shown by the probability value ( $P$ value) of it. Microsoft Excel was used to calculate the lines and statistical values of linear regression analysis. The $P$ value from the analysis is the test for the significant level $\alpha=0.05$.

The value of $R$-square $\left(R^{2}\right)$ or the square of the correlation from the regression analysis was used to show how strong the correlation and relationship between the variables $X$ and $Y$ are. The value is a fraction between 0.0 and 1.0. An $R^{2}$ value of 1.0 means that the correlation becomes strong and all points lie on a straight line. On the other hand, an $R^{2}$ value of 0.0 means that there is no correlation and no linear relationship between $X$ and $Y$.

\section{Results and Discussion}

\subsection{Hypothesis Testing}

$\mathrm{H}_{0}$ : there is no significant difference in the mean annual rainfall among the climatic zones in the Volta Region over the period of thirty years.

$\mathrm{H}_{1}$ : there is significant difference in the mean annual rainfall among the climatic zones in the Volta Region over the period of thirty years.

Table 1 shows an ANOVA to determine whether significant difference existed in the mean annual rainfall among the three climatic zones in the region. The results indicated that the difference in annual rainfall among the zones was highly significant $(F=42.55, P=0.000)$. The hypothesis that there is no significant difference in the mean annual rainfall among the climatic zones in the Volta Region over the period of thirty years is therefore rejected.

To determine which of the zones actually differed in terms of mean annual rainfall, the multiple mean comparisons were performed using LSD (the LSD was used because the ANOVA revealed that there were differences in the climatic zones). The results in Table 2 indicated that the mean difference in annual rainfall among the zones was highly significant, except that of northern and middle zones. Here the mean difference in annual rainfall observed over the period in the two zones was not statistically significant (mean diff. $=7.673 \mathrm{~mm}, P=$ 0.157).

From Figure 3 it is evident that the annual rainfall among the zones under consideration could best be described as oscillatory. The trend is not regular but irregular. However comparing the three zones, it can be observed that the middle zone trend is more regular than the rest. Additionally, the northern zone has the highest oscillatory trend of rainfall. The higher precipitation recorded in the northern zone generally could be attributed to the mountainous nature of the area, coupled with thick forests and also the Volta River which supply the bulk of the atmospheric moisture for precipitation. The low rainfall at coastal zone could be attributed to the vegetationless nature of the area. The loss of vegetation in these areas, compared to that of forest and mountainous areas, reduces natural cooling provided by evapotranspiration, the process through which intercepted radiation is utilized by plants, soils, and water bodies to
TABLE 1: Analysis of variance of mean annual rainfall among coastal, middle, and northern zones of Volta Region in Ghana from 1981 to 2011.

\begin{tabular}{lccccc}
\hline & $\begin{array}{c}\text { Sum of } \\
\text { squares }\end{array}$ & Df & $\begin{array}{c}\text { Mean } \\
\text { square }\end{array}$ & $F$ & $P$ value \\
\hline Between groups & 36877.748 & 2 & 18438.874 & 42.55 & .000 \\
Within groups & 37699.022 & 87 & 433.322 & & \\
\hline Total & 74576.770 & 89 & & & \\
\hline$P \leq 0.001$ & & & &
\end{tabular}

$P \leq 0.001$.

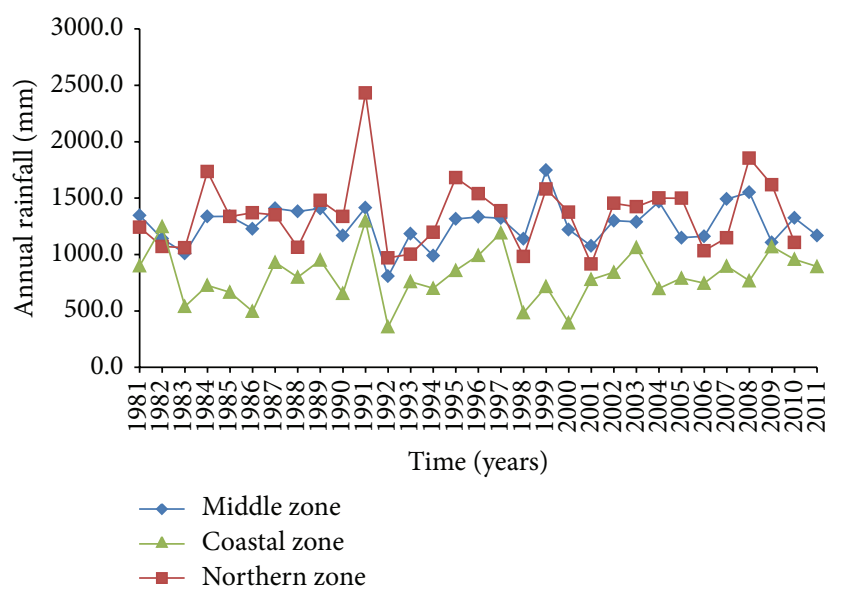

FIGURE 3: Fluctuation of rainfall for the three zones (1981-2011).

convert water to water vapour [7]. This water vapour rises to the upper atmosphere, condenses, and eventually falls as rain. However, $[8,9]$ averred that since rainfall in the tropics is extremely variable in both space and time, identifying the precise cause of fluctuations remains problematic.

From Table 3, the year with the highest annual rainfall was 1991, which recorded an amount of $1298.1 \mathrm{~mm}$ with a corresponding highest mean value of $108.2 \mathrm{~mm}$. The record indicated the standard deviation correlating the highest annual rainfall was $148.9 \mathrm{~mm}$ and the data was skewed right, meaning the rainfall distribution is flat. However, the maximum annual rainfall standard deviation occurred in 1997, with a value of $168.08 \mathrm{~mm}$, meaning the rainfall was highly dispersed or there was inconsistency in the rainfall pattern in 1997, with the corresponding highest range value. This observation again was buttressed by the highest variance and coefficient of variation figures recorded, respectively. According to Dewar and Wallis [10], the variation of CV values indicates the existence of strong variability in the rainfall of the study area. Nonetheless the maximum monthly rainfall occurred in 1997 in June. In addition, the lowest annual rainfall occurred in 1992 with an amount of $359.2 \mathrm{~mm}$ and a corresponding annual mean value of $29.9 \mathrm{~mm}$.

In Table 4, it can be inferred that the maximum annual rainfall of $1747.6 \mathrm{~mm}$ and the corresponding mean of $145.6 \mathrm{~mm}$ occurred in 1999 for the period under consideration. The minimum annual rainfall occurred in 1992 $(808.1 \mathrm{~mm})$ and the maximum annual standard deviation of 
TABLE 2: LSD multiple comparisons of mean annual rainfall of the climatic zones in Volta Region from 1981 to 2011.

\begin{tabular}{|c|c|c|c|c|c|}
\hline \multirow{2}{*}{ Zones } & \multirow{2}{*}{$(J)$ zone } & \multirow{2}{*}{ Mean difference $(I-J)$} & \multirow{2}{*}{$P$ value } & \multicolumn{2}{|c|}{ 95\% confidence interval } \\
\hline & & & & Lower bound & Upper bound \\
\hline \multirow{2}{*}{ Northern zone } & Middle zone & 7.673 & .157 & -3.01 & 18.3556 \\
\hline & Coastal zone & $46.260^{*}$ & .000 & 35.57 & 56.9426 \\
\hline \multirow{2}{*}{ Middle zone } & Northern zone & -7.673 & .157 & -18.35 & 3.0103 \\
\hline & Coastal zone & $38.587^{*}$ & .000 & 27.90 & 49.2699 \\
\hline \multirow{2}{*}{ Coastal zone } & Northern zone & $-46.260^{*}$ & .000 & -56.94 & -35.5767 \\
\hline & Middle zone & $-38.587^{*}$ & .000 & -49.26 & -27.9040 \\
\hline
\end{tabular}

${ }^{*}$ The mean difference is significant at the 0.05 level.

TABLE 3: Descriptive statistics of annual rainfall data of coastal zone.

\begin{tabular}{|c|c|c|c|c|c|c|c|c|c|c|}
\hline \multirow{2}{*}{ Year } & \multicolumn{10}{|c|}{ Parameters } \\
\hline & $\begin{array}{c}\text { Annual } \\
(\mathrm{mm})\end{array}$ & $\begin{array}{l}\text { Mean } \\
(\mathrm{mm})\end{array}$ & $\begin{array}{c}\text { Median } \\
(\mathrm{mm})\end{array}$ & $\begin{array}{l}\text { S.D. } \\
(\mathrm{mm})\end{array}$ & $\begin{array}{c}\text { Variance } \\
(\mathrm{mm})\end{array}$ & Skewness & Kurtosis & $\begin{array}{c}\text { Min } \\
(\mathrm{mm})\end{array}$ & $\begin{array}{l}\operatorname{Max} \\
(\mathrm{mm})\end{array}$ & $\begin{array}{l}\text { Range } \\
(\mathrm{mm})\end{array}$ \\
\hline 1981 & 899.4 & 75.0 & 43.2 & 81.4 & 6634.9 & 1.1 & -0.3 & 1.1 & 219.6 & 218.5 \\
\hline 1982 & 1247.5 & 104.0 & 60.6 & 139.7 & 19519.8 & 1.7 & 2.9 & 0.0 & 457.3 & 457.3 \\
\hline 1983 & 539.7 & 45.0 & 11.2 & 65.7 & 4324.2 & 1.4 & 0.9 & 0.0 & 183.2 & 183.2 \\
\hline 1984 & 726.9 & 60.6 & 23.8 & 76.4 & 5851.3 & 1.3 & 0.5 & 0.0 & 210.3 & 210.3 \\
\hline 1985 & 665.6 & 55.5 & 36.0 & 60.6 & 3680.5 & 1.5 & 2.5 & 0.0 & 206.8 & 206.8 \\
\hline 1986 & 495.8 & 41.3 & 32.0 & 42.4 & 1798.2 & 0.7 & -0.4 & 0.0 & 127.6 & 127.6 \\
\hline 1987 & 931.0 & 77.6 & 27.8 & 102.1 & 10438.4 & 1.7 & 3.1 & 0.0 & 339.9 & 339.9 \\
\hline 1988 & 798.3 & 66.5 & 72.1 & 51.1 & 2614.5 & -0.1 & -1.5 & 0.0 & 143.2 & 143.2 \\
\hline 1989 & 949.9 & 79.2 & 43.9 & 82.7 & 6847.9 & 0.5 & -1.4 & 0.0 & 213.8 & 213.8 \\
\hline 1990 & 655.9 & 54.7 & 46.6 & 47.2 & 2236.4 & 0.5 & -1.0 & 0.0 & 131.7 & 131.7 \\
\hline 1991 & 1298.1 & 108.2 & 30.8 & 148.9 & 22176.2 & 1.4 & 0.9 & 0.0 & 443.5 & 443.5 \\
\hline 1992 & 359.2 & 29.9 & 10.4 & 51.1 & 2614.6 & 2.5 & 6.7 & 0.0 & 176.5 & 176.5 \\
\hline 1993 & 759.3 & 63.3 & 64.9 & 44.8 & 2008.1 & 0.1 & -0.9 & 0.0 & 132.3 & 132.3 \\
\hline 1994 & 700.9 & 58.4 & 37.5 & 66.1 & 4365.8 & 1.4 & 1.4 & 0.0 & 207.9 & 207.9 \\
\hline 1995 & 859.2 & 71.6 & 31.5 & 94.1 & 8858.3 & 2.0 & 4.2 & 0.0 & 321.1 & 321.1 \\
\hline 1996 & 992.1 & 82.7 & 36.5 & 103.9 & 10793.1 & 1.1 & 0.0 & 0.0 & 283.8 & 283.8 \\
\hline 1997 & 1191.2 & 99.3 & 29.0 & 168.1 & 28252.3 & 2.7 & 8.3 & 0.0 & 598.3 & 598.3 \\
\hline 1998 & 484.4 & 40.4 & 14.1 & 58.3 & 3399.8 & 1.7 & 2.4 & 0.0 & 183.6 & 183.6 \\
\hline 1999 & 716.0 & 59.7 & 31.9 & 74.7 & 5590.8 & 1.6 & 1.5 & 2.8 & 223.6 & 220.8 \\
\hline 2000 & 394.3 & 32.9 & 21.9 & 34.8 & 1213.3 & 0.7 & -0.7 & 0.0 & 100.1 & 100.1 \\
\hline 2001 & 779.2 & 64.9 & 23.7 & 74.7 & 5587.9 & 0.7 & -1.4 & 0.0 & 189.4 & 189.4 \\
\hline 2002 & 842.6 & 70.2 & 45.6 & 89.8 & 8065.9 & 2.1 & 4.9 & 0.0 & 315.3 & 315.3 \\
\hline 2003 & 1061.9 & 88.5 & 30.9 & 131.8 & 17377.8 & 2.1 & 4.7 & 3.5 & 446.4 & 442.9 \\
\hline 2004 & 698.4 & 58.2 & 49.1 & 53.9 & 2904.5 & 0.6 & -0.9 & 0.0 & 147.3 & 147.3 \\
\hline 2005 & 790.8 & 65.9 & 57.9 & 61.9 & 3841.2 & 0.3 & -1.6 & 0.0 & 157.3 & 157.3 \\
\hline 2006 & 746.0 & 62.2 & 36.7 & 67.9 & 4617.8 & 0.9 & -0.1 & 0.0 & 202.4 & 202.4 \\
\hline 2007 & 897.1 & 74.8 & 56.5 & 71.2 & 5077.8 & 1.0 & 0.7 & 0.0 & 232.0 & 232.0 \\
\hline 2008 & 767.3 & 63.9 & 39.6 & 71.4 & 5108.2 & 1.5 & 1.4 & 0.0 & 213.2 & 213.2 \\
\hline 2009 & 1070.0 & 89.2 & 27.7 & 139.8 & 19570.4 & 2.2 & 5.5 & 0.2 & 477.3 & 477.1 \\
\hline 2010 & 957.4 & 79.8 & 78.5 & 73.6 & 5416.9 & 0.6 & -0.4 & 0.0 & 224.3 & 224.3 \\
\hline 2011 & 893.5 & 74.5 & 57.2 & 86.7 & 7522.1 & 1.4 & 2.1 & 0.0 & 285.7 & 285.7 \\
\hline
\end{tabular}


TABLE 4: Descriptive statistics of annual rainfall of middle zone.

\begin{tabular}{|c|c|c|c|c|c|c|c|c|c|c|}
\hline \multirow{2}{*}{ Year } & \multicolumn{10}{|c|}{ Parameters } \\
\hline & $\begin{array}{c}\text { Annual } \\
(\mathrm{mm})\end{array}$ & $\begin{array}{l}\text { Mean } \\
(\mathrm{mm})\end{array}$ & $\begin{array}{c}\text { Median } \\
(\mathrm{mm})\end{array}$ & $\begin{array}{l}\text { S.D. } \\
(\mathrm{mm})\end{array}$ & $\begin{array}{c}\text { Variance } \\
(\mathrm{mm})\end{array}$ & Skewness & Kurtosis & $\begin{array}{l}\text { Min } \\
(\mathrm{mm})\end{array}$ & $\begin{array}{c}\operatorname{Max} \\
(\mathrm{mm})\end{array}$ & $\begin{array}{l}\text { Range } \\
(\mathrm{mm})\end{array}$ \\
\hline 1981 & 1346.7 & 112.2 & 95.7 & 94.9 & 9013.6 & 1.4 & 1.4 & 0.0 & 319.8 & 319.8 \\
\hline 1982 & 1141.2 & 95.1 & 90.5 & 61.5 & 3788.0 & 1.1 & 0.6 & 30.7 & 230.1 & 199.4 \\
\hline 1983 & 1010.2 & 84.2 & 90.5 & 66.9 & 4482.4 & -0.1 & -2.1 & 0.0 & 163.4 & 163.4 \\
\hline 1984 & 1337.2 & 111.4 & 120.9 & 92.0 & 8470.2 & 0.1 & -1.4 & 0.0 & 265.7 & 265.7 \\
\hline 1985 & 1338.4 & 111.5 & 125.3 & 78.7 & 6202.6 & 0.4 & 1.0 & 2.8 & 283.6 & 280.8 \\
\hline 1986 & 1228.1 & 102.3 & 108.8 & 76.5 & 5855.3 & 0.0 & -1.4 & 0.0 & 212.7 & 212.7 \\
\hline 1987 & 1409.0 & 117.4 & 122.0 & 89.5 & 8021.7 & 0.1 & -1.1 & 7.7 & 254.1 & 246.4 \\
\hline 1988 & 1382.2 & 115.2 & 109.2 & 65.7 & 4319.9 & 0.1 & -1.3 & 21.4 & 223.1 & 201.7 \\
\hline 1989 & 1408.5 & 117.4 & 130.8 & 101.9 & 10382.0 & 0.8 & 1.0 & 0.0 & 346.4 & 346.4 \\
\hline 1990 & 1167.7 & 97.3 & 109.3 & 71.7 & 5143.3 & 0.4 & -0.8 & 14.6 & 224.7 & 210.1 \\
\hline 1991 & 1415.2 & 117.9 & 102.4 & 93.3 & 8708.8 & 0.8 & 0.7 & 3.1 & 325.4 & 322.3 \\
\hline 1992 & 808.1 & 67.3 & 66.4 & 48.7 & 2380.7 & 0.3 & -0.1 & 0.0 & 164.2 & 164.2 \\
\hline 1993 & 1184.8 & 98.7 & 94.8 & 57.5 & 3308.8 & 0.0 & -0.2 & 0.0 & 204.2 & 204.2 \\
\hline 1994 & 990.0 & 82.5 & 66.0 & 69.9 & 4887.3 & 1.2 & 1.1 & 0.0 & 239.9 & 239.9 \\
\hline 1995 & 1315.0 & 109.6 & 119.6 & 71.8 & 5166.8 & -0.2 & -1.3 & 0.0 & 209.8 & 209.8 \\
\hline 1996 & 1333.8 & 111.2 & 86.4 & 86.7 & 7526.9 & 0.9 & 0.2 & 5.1 & 282.9 & 277.8 \\
\hline 1997 & 1322.7 & 110.2 & 95.9 & 79.4 & 6314.1 & 0.3 & -1.2 & 13.7 & 248.6 & 234.9 \\
\hline 1998 & 1140.3 & 95.0 & 89.8 & 67.2 & 4524.6 & 0.8 & 0.6 & 0.3 & 242.4 & 242.1 \\
\hline 1999 & 1747.6 & 145.6 & 119.5 & 113.3 & 12859.2 & 0.7 & -0.1 & 0.5 & 374.4 & 373.9 \\
\hline 2000 & 1220.8 & 101.7 & 94.8 & 70.4 & 4967.6 & 0.2 & -1.6 & 10.6 & 194.8 & 184.2 \\
\hline 2001 & 1076.4 & 89.7 & 84.1 & 73.0 & 5338.1 & 0.1 & -1.5 & 0.0 & 192.9 & 192.9 \\
\hline 2002 & 1300.3 & 108.4 & 119.4 & 61.8 & 3822.2 & -0.5 & -1.3 & 6.7 & 175.3 & 168.6 \\
\hline 2003 & 1289.4 & 107.5 & 79.2 & 92.4 & 8550.8 & 1.2 & 1.3 & 10.6 & 324.9 & 314.3 \\
\hline 2004 & 1468.5 & 122.4 & 102.3 & 124.0 & 15380.9 & 2.0 & 4.5 & 3.9 & 454.2 & 450.3 \\
\hline 2005 & 1148.7 & 95.7 & 68.6 & 55.8 & 3121.1 & 0.5 & -1.5 & 41.2 & 185.6 & 144.4 \\
\hline 2006 & 1161.7 & 96.8 & 69.7 & 88.5 & 7835.3 & 1.2 & 0.8 & 5.0 & 289.2 & 284.2 \\
\hline 2007 & 1491.7 & 124.3 & 125.4 & 90.1 & 8120.3 & 0.1 & -1.1 & 0.2 & 262.0 & 261.8 \\
\hline 2008 & 1551.5 & 129.3 & 141.1 & 78.7 & 6198.5 & -0.3 & -1.1 & 0.0 & 239.0 & 239.0 \\
\hline 2009 & 1106.6 & 92.2 & 87.4 & 66.5 & 4425.1 & 0.6 & -0.2 & 0.0 & 224.0 & 224.0 \\
\hline 2010 & 1324.4 & 110.4 & 96.9 & 78.6 & 6192.1 & 0.2 & -1.6 & 6.0 & 227.0 & 221.0 \\
\hline 2011 & 1168.8 & 116.9 & 133.3 & 57.3 & 3286.7 & -0.8 & 0.7 & 0.0 & 197.2 & 197.2 \\
\hline
\end{tabular}

$124 \mathrm{~mm}$ happened in 2004. The high standard deviation value can be easily correlated with the high rainfall range. The rainfall range signifies the difference between the maximum and minimum annual rainfall. The standard deviation and the range indicate the variability of annual rainfall and hence denote how reliable the rainfall is in terms of its persistence as constant and stable replenishing source. To test whether the annual rainfall data follow a normal distribution, the skewness and kurtosis were computed. Skewness is a measure of symmetry or, more precisely, the lack of symmetry. The data set is said to be symmetric if it looks the same to the left and right from the center point. The skewness for a normal distribution is zero, and any symmetric data should have skewness near zero. Negative values for the skewness indicate that data are skewed to the left and positive values for the skewness indicate that data are skewed to the right.
Kurtosis is a measure of data peakedness or flatness relative to a normal distribution. That is, data sets with a high kurtosis tend to have a distinct peak near the mean, decline rather rapidly, and have heavy tails. Data sets with low kurtosis tend to have a flat top near the mean rather than a sharp peak. The standard normal distribution has a kurtosis of zero. Positive kurtosis indicates a peaked distribution and negative kurtosis indicates a flat distribution. Hence the annual rainfall distribution under consideration did not follow normal distribution.

As can be observed from Table 5 the maximum annual rainfall for the period under review occurred in 1991 $(2431.5 \mathrm{~mm})$ with corresponding maximum annual mean and standard deviation of $202.6 \mathrm{~mm}$ and $182.8 \mathrm{~mm}$, respectively. The standard deviation is a measure of dispersion. A small value indicates that the data is tightly grouped about 
TABLE 5: Descriptive statistics of annual rainfall of northern zone.

\begin{tabular}{|c|c|c|c|c|c|c|c|c|c|c|}
\hline \multirow{2}{*}{ Year } & \multicolumn{10}{|c|}{ Parameters } \\
\hline & $\begin{array}{c}\text { Annual } \\
(\mathrm{mm})\end{array}$ & $\begin{array}{l}\text { Mean } \\
(\mathrm{mm})\end{array}$ & $\begin{array}{c}\text { Median } \\
(\mathrm{mm})\end{array}$ & $\begin{array}{l}\text { S.D. } \\
(\mathrm{mm})\end{array}$ & $\begin{array}{c}\text { Variance } \\
(\mathrm{mm})\end{array}$ & Skewness & kurtosis & $\begin{array}{c}\text { Min } \\
(\mathrm{mm})\end{array}$ & $\begin{array}{c}\operatorname{Max} \\
(\mathrm{mm})\end{array}$ & $\begin{array}{l}\text { Range } \\
(\mathrm{mm})\end{array}$ \\
\hline 1981 & 1241.6 & 103.5 & 83.7 & 96.4 & 9298.6 & 0.2 & -1.8 & 0.0 & 239.4 & 239.4 \\
\hline 1982 & 1071.8 & 89.3 & 99.6 & 68.1 & 4642.2 & 0.1 & -1.0 & 0.0 & 204.8 & 204.8 \\
\hline 1983 & 1060.7 & 88.4 & 60.9 & 95.2 & 9068.9 & 0.8 & -0.6 & 0.0 & 273.9 & 273.9 \\
\hline 1984 & 1735.2 & 144.6 & 77.1 & 150.6 & 22682.2 & 0.6 & -1.3 & 0.0 & 384.1 & 384.1 \\
\hline 1985 & 1336.8 & 111.4 & 83.0 & 112.5 & 12659.3 & 0.5 & -1.6 & 0.0 & 284.0 & 284.0 \\
\hline 1986 & 1370.1 & 114.2 & 108.6 & 97.8 & 9571.7 & -0.0 & -2.0 & 0.0 & 229.2 & 229.2 \\
\hline 1987 & 1351.4 & 112.6 & 84.8 & 126.5 & 16004.2 & 1.1 & 0.8 & 0.0 & 398.1 & 398.1 \\
\hline 1988 & 1064.4 & 88.7 & 56.2 & 88.4 & 7825.1 & 0.6 & -1.2 & 0.0 & 246.2 & 246.2 \\
\hline 1989 & 1479.5 & 123.3 & 23.4 & 161.7 & 26155.4 & 1.1 & -0.2 & 0.0 & 430.2 & 430.2 \\
\hline 1990 & 1336.7 & 111.4 & 114.4 & 97.7 & 9553.3 & 0.4 & -0.8 & 0.0 & 296.5 & 296.5 \\
\hline 1991 & 2431.5 & 202.6 & 179.6 & 182.8 & 33425.1 & 0.3 & -1.4 & 0.0 & 498.1 & 498.1 \\
\hline 1992 & 970.7 & 88.2 & 58.9 & 88.7 & 7872.5 & 0.7 & -0.4 & 0.0 & 257.4 & 257.4 \\
\hline 1993 & 1003.2 & 83.6 & 44.8 & 95.1 & 9052.5 & 1.5 & 2.1 & 0.0 & 316.3 & 316.3 \\
\hline 1994 & 1197.9 & 99.8 & 116.8 & 93.7 & 8780.1 & 0.0 & -1.9 & 0.0 & 226.9 & 226.9 \\
\hline 1995 & 1680.8 & 140.1 & 145.6 & 125.7 & 15821.9 & 0.2 & -1.4 & 0.0 & 350.4 & 350.4 \\
\hline 1996 & 1539.8 & 128.3 & 149.1 & 119.2 & 14226.2 & -0.1 & -2.1 & 0.0 & 274.6 & 274.6 \\
\hline 1997 & 1387.9 & 115.7 & 84.8 & 107.8 & 11635.4 & 0.4 & -1.5 & 0.0 & 277.2 & 277.2 \\
\hline 1998 & 982.5 & 89.3 & 60.3 & 81.1 & 6583.3 & 0.2 & -1.7 & 0.0 & 205.5 & 205.5 \\
\hline 1999 & 1580.8 & 131.7 & 64.9 & 142.4 & 20300.0 & 0.8 & -0.9 & 0.0 & 394.4 & 394.4 \\
\hline 2000 & 1375.6 & 114.6 & 85.0 & 109.4 & 11972.7 & 0.5 & -1.3 & 0.0 & 293.2 & 293.2 \\
\hline 2001 & 915.6 & 76.3 & 38.7 & 100.1 & 10016.8 & 1.3 & 0.7 & 0.0 & 291.8 & 291.8 \\
\hline 2002 & 1453.8 & 121.2 & 155.1 & 97.7 & 9550.9 & -0.2 & -1.8 & 0.0 & 240.7 & 240.7 \\
\hline 2003 & 1423.5 & 118.6 & 95.0 & 110.0 & 12101.4 & 0.9 & -0.5 & 0.7 & 314.0 & 313.3 \\
\hline 2004 & 1500.6 & 125.1 & 109.4 & 110.2 & 12157.7 & 0.6 & -0.8 & 0.0 & 322.8 & 322.8 \\
\hline 2005 & 1498.8 & 124.9 & 95.7 & 121.3 & 14727.5 & 1.0 & 0.1 & 0.0 & 374.3 & 374.3 \\
\hline 2006 & 1033.3 & 86.1 & 62.7 & 96.5 & 9314.4 & 1.2 & 0.7 & 0.4 & 284.6 & 284.2 \\
\hline 2007 & 1148.6 & 95.7 & 89.1 & 76.3 & 5820.8 & 0.1 & -1.6 & 0.0 & 208.9 & 208.9 \\
\hline 2008 & 1853.5 & 154.5 & 133.6 & 151.0 & 22802.6 & 0.8 & 0.2 & 0.0 & 479.1 & 479.1 \\
\hline 2009 & 1617.5 & 134.8 & 139.1 & 109.4 & 11981.1 & 0.1 & -1.7 & 0.0 & 294.7 & 294.7 \\
\hline 2010 & 1107.2 & 92.3 & 86.3 & 82.0 & 6729.4 & 0.6 & -0.3 & 0.0 & 244.5 & 244.5 \\
\hline
\end{tabular}

the mean. A high value indicates that the data is spread widely on either side of the mean. A high standard deviation also suggests that year-to-year fluctuations are high while a low standard deviation indicates that fluctuations are lower. In other words, rainfall with a high standard deviation is considered more volatile than rainfall with a low figure. The minimum annual rainfall occurred in 2001 with an amount of $915.6 \mathrm{~mm}$ for the years under consideration.

It is evident from Table 6 that the coefficient of variation for the months of April through July (major season) is less than 0.5 which indicates lower variability from the mean and similar observation is made for the months of September and October (minor season). The low coefficient of variability recorded for the aforementioned months is an indication of highly dependable rainfall. Reference [11] stated that the $\mathrm{CV}$ is an indication of the degree of precision to which the treatments are compared and is a good index of the reliability of the experiment. Reference [11] further indicated that the higher the CV value, the lower the reliability of the experiment.

The standard deviation is one way of summarizing the spread of a probability distribution; it relates directly to the degree of uncertainty associated with predicting the value of a random variable. High values reflect more uncertainty than low values. Table 6 clearly revealed that September in middle climatic zone had the highest standard deviation. The highest amount of average monthly rainfall was recorded in June $(182.1 \mathrm{~mm})$ and contributed to $14.3 \%$ of annual rainfall, followed by September with $12.8 \%$, and the lowest was in January with $1.4 \%$ of annual total followed by December with $2.3 \%$. From the analysis, it was observed that rainfall is usually at its peak between April and July in the major season and between September and October in the minor season.

The precipitation changes from month to month are considerable in years. When the standard deviation values are examined, it is observed that the standard deviation values 
TABLE 6: Statistical summary of monthly rainfall data of middle zone.

\begin{tabular}{lcccccccccccc}
\hline Parameter $(\mathrm{mm})$ & Jan & Feb & Mar & Apr & May & Jun & Jul & Aug & Sep & Oct & Nov & Dec \\
\hline Mean & 18.2 & 52.7 & 102.3 & 133.3 & 154.9 & 182.1 & 132.2 & 94.6 & 163.2 & 160.3 & 47.3 & 30.4 \\
Median & 8.2 & 43.5 & 100.2 & 132.0 & 147.9 & 165.1 & 120.0 & 84.4 & 164.2 & 154.8 & 42.0 & 21.6 \\
S.D. & 22.2 & 44.8 & 59.6 & 57.2 & 66.8 & 78.3 & 58.2 & 66.4 & 79.5 & 52.9 & 32.3 & 32.2 \\
Variance & 490.9 & 2009.3 & 3553.4 & 3274.6 & 4460.5 & 6127.1 & 3384.8 & 4403.6 & 6332.2 & 2801.6 & 1041.9 & 1039.6 \\
Skewness & 1.1 & 2.0 & 0.8 & -0.1 & 0.7 & 0.9 & 0.5 & 0.7 & 1.5 & 0.9 & 1.4 & 0.9 \\
Kurtosis & 0.4 & 4.9 & 0.5 & -0.2 & 0.2 & 0.2 & 0.1 & -0.3 & 4.9 & 1.5 & 1.7 & -0.2 \\
Min & 0.0 & 5.8 & 20.3 & 6.9 & 35.5 & 74.4 & 30.2 & 9.4 & 47.5 & 77.4 & 5.8 & 0.0 \\
Max & 78.4 & 212.7 & 265.7 & 255.6 & 325.4 & 374.4 & 283.6 & 254.1 & 454.2 & 319.8 & 133.8 & 103.4 \\
Range & 78.4 & 206.9 & 245.4 & 248.7 & 289.9 & 300.0 & 253.4 & 244.7 & 406.7 & 242.4 & 128.0 & 103.4 \\
Sum & 564.0 & 1632.8 & 3169.9 & 4132.9 & 4800.7 & 5645.0 & 4097.1 & 2933.1 & 5060.3 & 4968.1 & 1419.8 & 911.8 \\
CV & 1.2 & 0.9 & 0.6 & 0.4 & 0.4 & 0.4 & 0.4 & 0.7 & 0.4 & 0.3 & 0.6 & 1.0 \\
\hline
\end{tabular}

TABLE 7: Statistical summary of monthly rainfall data of coastal zone.

\begin{tabular}{|c|c|c|c|c|c|c|c|c|c|c|c|c|}
\hline Parameters & Jan & Feb & Mar & Apr & May & Jun & Jul & Aug & Sep & Oct & Nov & Dec \\
\hline Mean (mm) & 3.3 & 23.2 & 61.0 & 107.3 & 150.4 & 206.2 & 64.9 & 19.8 & 56.0 & 78.7 & 29.9 & 11.2 \\
\hline Median (mm) & 0.0 & 11.2 & 49.0 & 86.7 & 145.7 & 174.2 & 44.2 & 10.8 & 33.9 & 65.2 & 22.0 & 2.5 \\
\hline S.D. $(\mathrm{mm})$ & 6.1 & 30.8 & 45.8 & 67.8 & 60.4 & 138.5 & 87.6 & 31.7 & 71.0 & 63.2 & 29.0 & 18.3 \\
\hline Variance (mm) & 36.8 & 950.2 & 2098.5 & 4606.9 & 3645.8 & 19185.3 & 7675.3 & 1005.1 & 5050.3 & 3997.5 & 841.2 & 336.0 \\
\hline Skewness & 2.2 & 1.4 & 0.7 & 1.2 & 0.0 & 1.2 & 3.0 & 3.2 & 2.5 & 0.6 & 0.8 & 2.6 \\
\hline Kurtosis & 4.8 & 0.9 & -0.0 & 1.9 & -0.5 & 1.1 & 11.4 & 12.9 & 7.7 & -0.8 & -0.1 & 6.9 \\
\hline $\operatorname{Min}(\mathrm{mm})$ & 0.0 & 0.0 & 0.0 & 18.3 & 34.5 & 47.0 & 1.2 & 0.0 & 0.0 & 0.5 & 0.0 & 0.0 \\
\hline $\operatorname{Max}(\mathrm{mm})$ & 22.6 & 96.3 & 181.1 & 324.7 & 269.6 & 598.3 & 443.5 & 160.6 & 339.9 & 210.9 & 107.6 & 77.7 \\
\hline Range (mm) & 22.6 & 96.3 & 181.1 & 306.4 & 235.1 & 551.3 & 442.3 & 160.6 & 339.9 & 210.4 & 107.6 & 77.7 \\
\hline Sum (mm) & 102.0 & 719.5 & 1890.7 & 3325.0 & 4663.9 & 6391.7 & 2012.5 & 612.4 & 1735.9 & 2440.0 & 928.3 & 347.0 \\
\hline $\mathrm{CV}$ & 1.8 & 1.3 & 0.7 & 0.6 & 0.4 & 0.6 & 1.3 & 1.6 & 1.2 & 0.8 & 0.9 & 1.6 \\
\hline
\end{tabular}

of most months (January, February, July, August, September, and December) are higher than the averages of these months (See Table 7). This relation between the standard deviation and the average values indicates that the deviation from the normal distribution cannot be ignored. This fact is especially supported by the coefficients of variation of these months which are over one or close to one. These show that, in coastal zones, the precipitation values are much different from the average. The fact that the CV values are so high is an indication of the rainfall being highly variable and not dependable or reliable or can be attributed to the length of data set being used or the quality of data.

The lower the coefficient of variation of rainfall amount in any month, the lower the variability and the greater the dependability. Coefficient of variation values less than 0.5 shows lower variability from the mean. Table 8 reveals that from June to September the rainfall variability is low and therefore highly dependable. Considering the coefficient of variation, September shows the minimum variation from year to year, compared to the rest of the months. However, since the coefficients of variation of each of the four months (June-September) are less than 0.5, the changes of precipitation from year to year in these months are low. September is the month with the highest mean monthly rainfall of $252.3 \mathrm{~mm}$ followed by August with $227.6 \mathrm{~mm}$. Incidentally the above mentioned months traditionally fall within the minor season which usually records lower rainfall. This change in the rainfall season could be attributed to the socalled climate change. The month with the lowest rainfall is December $(7.6 \mathrm{~mm})$ followed by January $(7.7 \mathrm{~mm})$.

The results of the linear regression trend analysis are presented in Tables 9, 10, and 11, respectively, covering northern, middle, and coastal zones, respectively, of the Volta Region. In these trend tests, trend of rainfall for 30 years from January to December has been computed for each month independently.

The linear trend lines of the monthly rainfall indicated a downward trend in May, June, and September and an upward trend for other months and annual rainfall data for the northern zone. Since the probability value ( $P$ value) from the regression analysis for the slopes of the monthly and annual trend lines was greater than the significant level $\alpha=$ 0.05 , the null hypothesis $\left(H_{0}\right.$ : there is no trend in the data, fail to reject. That means there is no statistically significant trend in the annual and monthly rainfall data for northern zone. Additionally, the $R$-square statistic also indicated a very weak relationship between the variables, rainfall, and year.

Table 10 revealed downward trends in the rainfall for the months of March, May, July, October, and November and the rest of the months recorded upward trend in the rainfall data 
TABLE 8: Statistical summary of monthly rainfall data of northern zone.

\begin{tabular}{|c|c|c|c|c|c|c|c|c|c|c|c|c|}
\hline Parameter & Jan & Feb & Mar & Apr & May & Jun & Jul & Aug & Sep & Oct & Nov & Dec \\
\hline Mean $(\mathrm{mm})$ & 7.7 & 11.1 & 38.2 & 93.9 & 128.8 & 217.2 & 210.9 & 227.6 & 252.3 & 142.5 & 22.2 & 7.6 \\
\hline Median (mm) & 0.0 & 0.3 & 35.2 & 82.3 & 125.4 & 213.5 & 201.9 & 243.6 & 235.2 & 119.8 & 6.3 & 0.7 \\
\hline S.D. $(\mathrm{mm})$ & 16.0 & 19.6 & 31.6 & 61.3 & 80.0 & 83.4 & 94.0 & 80.3 & 70.3 & 93.9 & 31.1 & 16.0 \\
\hline Variance $(\mathrm{mm})$ & 255.1 & 383.7 & 1000.6 & 3756.6 & 6394.8 & 6952.4 & 8831.9 & 6445.9 & 4947.0 & 8812.8 & 964.4 & 255.3 \\
\hline Skewness & 2.1 & 1.8 & 0.7 & 0.9 & 1.2 & 0.5 & 1.7 & -0.3 & 0.9 & 1.3 & 1.6 & 2.8 \\
\hline Kurtosis & 3.8 & 1.8 & 0.1 & 0.4 & 3.1 & 0.2 & 3.6 & -0.5 & 0.0 & 2.4 & 2.1 & 7.4 \\
\hline $\operatorname{Min}(\mathrm{mm})$ & 0.0 & 0.0 & 0.0 & 7.3 & 6.0 & 93.6 & 91.7 & 73.0 & 146.8 & 9.2 & 0.0 & 0.0 \\
\hline $\operatorname{Max}(\mathrm{mm})$ & 60.0 & 65.7 & 117.3 & 245.6 & 398.6 & 430.2 & 498.1 & 373.5 & 400.6 & 440.7 & 112.0 & 66.1 \\
\hline Range (mm) & 60.0 & 65.7 & 117.3 & 238.3 & 392.6 & 336.6 & 406.4 & 300.5 & 253.8 & 431.5 & 112.0 & 66.1 \\
\hline Sum $(\mathrm{mm})$ & 231.6 & 323.3 & 1107.5 & 2817.5 & 3864.7 & 6516.0 & 6326.4 & 6827.3 & 7567.5 & 4274.7 & 665.9 & 228.9 \\
\hline $\mathrm{CV}$ & 2.1 & 1.7 & 0.8 & 0.6 & 0.6 & 0.3 & 0.4 & 0.3 & 0.2 & 0.6 & 1.3 & 2.1 \\
\hline
\end{tabular}

TABLE 9: Regression statistic results for annual and monthly rainfall for northern zone.

\begin{tabular}{lcccc}
\hline Month & Regression equation & $R$-square & $P$ value & Statistically significant \\
\hline Jan & $Y=0.35 X-681.8$ & 0.04 & 0.32 & No \\
Feb & $Y=0.30 X-592.4$ & 0.02 & 0.47 & No \\
Mar & $Y=0.19 X-355.3$ & 0.00 & 0.80 & No \\
April & $Y=1.19 X-2285.5$ & 0.03 & 0.38 & No \\
May & $Y=-2.06 X+4231.2$ & 0.05 & 0.22 & No \\
June & $Y=-1.73+3672.1$ & 0.03 & 0.30 & No \\
July & $Y=0.91 X-1596.4$ & 0.01 & 0.69 & No \\
Aug & $Y=0.68 X-1126.2$ & 0.01 & 0.75 & No \\
Sept & $Y=-0.57 X+1392.3$ & 0.01 & 0.65 & No \\
Oct & $Y=1.73 X-3318.1$ & 0.03 & 0.41 & No \\
Nov & $Y=1.05 X-2064.5$ & 0.09 & 0.12 & No \\
Dec & $Y=0.47 X-927.3$ & 0.07 & 0.80 & No \\
Annual & $Y=2.51 X-3651.9$ & 0.00 & & \\
\hline
\end{tabular}

TABLE 10: Regression statistic results for annual and monthly rainfall for central zone.

\begin{tabular}{lcccc}
\hline Month & Regression equation & $R$-square & $P$ value & Statistically significant \\
\hline Jan & $Y=0.31 X-609.8$ & 0.02 & 0.50 & No \\
Feb & $Y=0.34 X-629.0$ & 0.00 & 0.73 & No \\
Mar & $Y=-0.99 X+2095.1$ & 0.02 & 0.39 & No \\
April & $Y=1.49 X-2856.9$ & 0.06 & 0.22 & No \\
May & $Y=-1.53 X+3212.6$ & 0.04 & 0.24 & No \\
June & $Y=2.33 X-4486.8$ & 0.07 & 0.15 & No \\
July & $Y=-0.97 X+2080.8$ & 0.02 & 0.38 & No \\
Aug & $Y=-0.47 X+1041.2$ & 0.00 & 0.70 & No \\
Sept & $Y=2.74 X-5315.2$ & 0.09 & 0.09 & No \\
Oct & $Y=-0.72 X+1594.7$ & 0.02 & 0.67 & No \\
Nov & $Y=-0.27 X+599.3$ & 0.01 & 0.77 & No \\
Dec & $Y=0.22 X-412.0$ & 0.00 & 0.71 & No \\
Annual & $Y=2.02 X-2760.5$ & 0.01 & & \\
\hline
\end{tabular}

for the middle zone. However, the trends are not statistically significant. This argument is buttressed by the $P$ values of the linear regression analysis being greater than $\alpha=0.05$.

Annual rainfall for coastal zone showed upward trend; however, there is a decreasing trend in the months of March, April, May, July, September, and November and the rest of the months of the year revealed an increasing trend. Again, these trends are insignificant statistically as indicated by the $P$ values.

Figure 4 clearly reveals that for the period under consideration for middle zone the highest mean monthly rainfall was recorded in June and the lowest in January. It is also 
TABLE 11: Regression statistic results for annual and monthly rainfall for coastal zone.

\begin{tabular}{lcccc}
\hline Month & Regression equation & $R$-square & $P$ value & Statistically significant \\
\hline Jan & $Y=0.80 X-154.7$ & 0.01 & 0.53 & No \\
Feb & $Y=0.90 X-1774.88$ & 0.07 & 0.15 & No \\
Mar & $Y=-1.16 X+2384.64$ & 0.05 & 0.20 & No \\
April & $Y=-0.35 X+811.97$ & 0.00 & 0.77 & No \\
May & $Y=-0.87 X+1881.74$ & 0.02 & 0.45 & No \\
June & $Y=3.38 X-6540.3$ & 0.05 & 0.24 & No \\
July & $Y=-1.65 X+3357.27$ & 0.03 & 0.35 & No \\
Aug & $Y=0.32 X-617.20$ & 0.01 & 0.64 & No \\
Sept & $Y=-0.04 X+132.05$ & 0.00 & 0.96 & No \\
Oct & $Y=1.66 X-3234.97$ & 0.06 & 0.21 & No \\
Nov & $Y=-0.26 X+545.28$ & 0.01 & 0.65 & No \\
Dec & $Y=0.18 X-353.72$ & 0.01 & 0.64 & No \\
Annual & $Y=2.19 X-3562.80$ & 0.01 & 0.70 & \\
\hline
\end{tabular}

evident from the graph that the highest average minor season rainfall occurred in September.

For the northern zone the highest average monthly rainfall for the period under review as indicated in Figure 4 was recorded in September which is a minor season for the northern climatic zone. The result clearly indicated that the peak mean monthly rainfall in the minor season was more than the major season which suggested a discrepancy. However, this could be attributed to climate change effects.

The graph for coastal zone revealed that December and January were the driest months. The highest rainfall occurred in June for the major season while the highest corresponding minor season rainfall was recorded in October.

\section{Conclusion}

The rainfall characteristics especially variability and trend are necessary for the proper design of hydro related schemes such as clean water supply, reservoir, and storm water channels in rapidly growing regions like Volta Region. From the results of the linear regression analysis, there is statistically insignificant increasing trend in annual mean rainfall data among the zones under study. The mean monthly rainfall data from the linear regression analysis revealed upward trend in some months and downward trend in others. However, the results indicated statistically insignificant trend in the monthly rainfall and very weak correlation between rainfall and period. It is evident from the results that there is no significant detectable effect of climate change on both the annual and monthly trend in Volta Region.

Comparatively coastal zone recorded the lowest maximum and minimum annual rainfall of $1298.1 \mathrm{~mm}$ and $359.2 \mathrm{~mm}$, respectively, followed by the middle zone with $1747.6 \mathrm{~mm}$ and $808.1 \mathrm{~mm}$. The northern zone recorded the highest maximum annual rainfall of $2431.5 \mathrm{~mm}$ and the minimum of $915.6 \mathrm{~mm}$ in the years 1991 and 2001, respectively.

Further studies are required to be carried out to establish other rainfall characteristics such as extreme rainfall, rain days, and other climate change parameters for this region to verify whether the significant trend has occurred and also

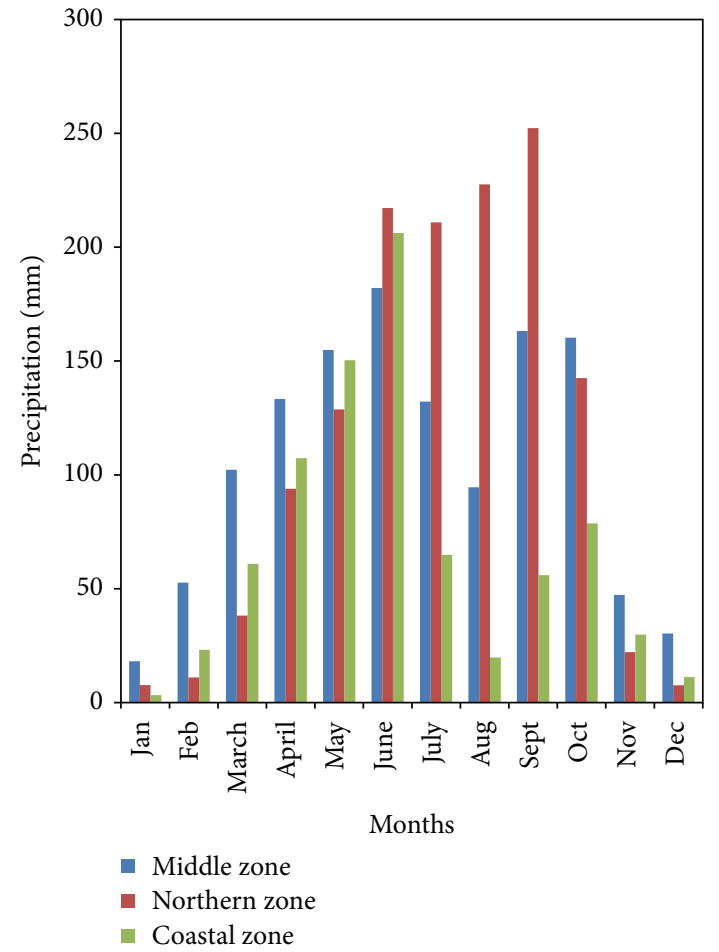

FIGURE 4: Average monthly rainfall for the three zones from 1981 to 2010.

to establish a correlation between temperature and extreme rainfall.

\section{Conflict of Interests}

The authors declare that there is no conflict of interests regarding the publication of this paper.

\section{References}

[1] R. F. Adler, G. J. Huffman, D. T. Bolvin, S. Curtis, and E. J. Nelkin, "Tropical rainfall distributions determined using 
TRMM combined with other satellite and rain gauge information," Journal of Applied Meteorology, vol. 39, no. 12, pp. 20072023, 2000.

[2] J. R. Gat, Planning and Management of a Sustainable and Equitable Water Supply under Stress of Water Scarcity and Quality Deterioration and the Constraints of Societal and Political Divisions: The Case for a Regional Holistic Approach. Department of Environmental Science and Energy Research, The Weizmann Institute of Science, Rehovot, Israel, 2004.

[3] E. C. Kipkorir, "Analysis of rainfall climate on the Njemps Flats, Baringo District, Kenya," Journal of Arid Environments, vol. 50, no. 3, pp. 445-458, 2002.

[4] S. Herath and U. Ratnayake, "Monitoring rainfall trends to predict adverse impacts-a case study from Sri Lanka (19641993)," Global Environmental Change, vol. 14, pp. 71-79, 2004.

[5] M. N. Almasri, A. Jayyousi, and A. Jarrar, "Statistical analysis of long-term spring yield in a semi-arid watershed: a case study from Palestine," in Proceedings of the International Conference Water: Values and Rights, Ramallah, Palestine, May 2005.

[6] Volta Regional Coordinating Council (VRRC), "Volta Region," 2013, http://www.ghananation.com/volta/.

[7] S. Brian Jr. and M. O. Rodgers, "Urban form and thermal efficiency how the design of cities influences the Urban heat island effect," Journal of the American Planning Association, vol. 67, no. 2, pp. 186-198, 2001.

[8] M. J. Manton and M. Bonell, "Climate and rainfall variability in the humid tropics," in Hydrology and Water Management in the Humid Tropics-Hydrological Research Issues and Strategies for Water Management, M. Bonell, M. M. Hufschmidt, and J. S. Gladwell, Eds., pp. 13-33, Cambridge University Press, Cambridge, UK, 1993.

[9] S. Nieuwolt, Tropical Climatology: An Introduction to the Climates of the Low Latitudes, John Wiley \& Sons, New York, NY, USA, 1977.

[10] R. E. Dewar and J. R. Wallis, "Geographical patterning of interannual rainfall variability in the tropics and near tropics: an L-moments approach," The American Meteorology Society, vol. 12, no. 12, pp. 3457-3466, 1999.

[11] K. A. Gomez and A. A. Gomez, Statistical Procedures for Agricultural Research, John Wiley \& Sons, New York, NY, USA, 2nd edition, 1984. 

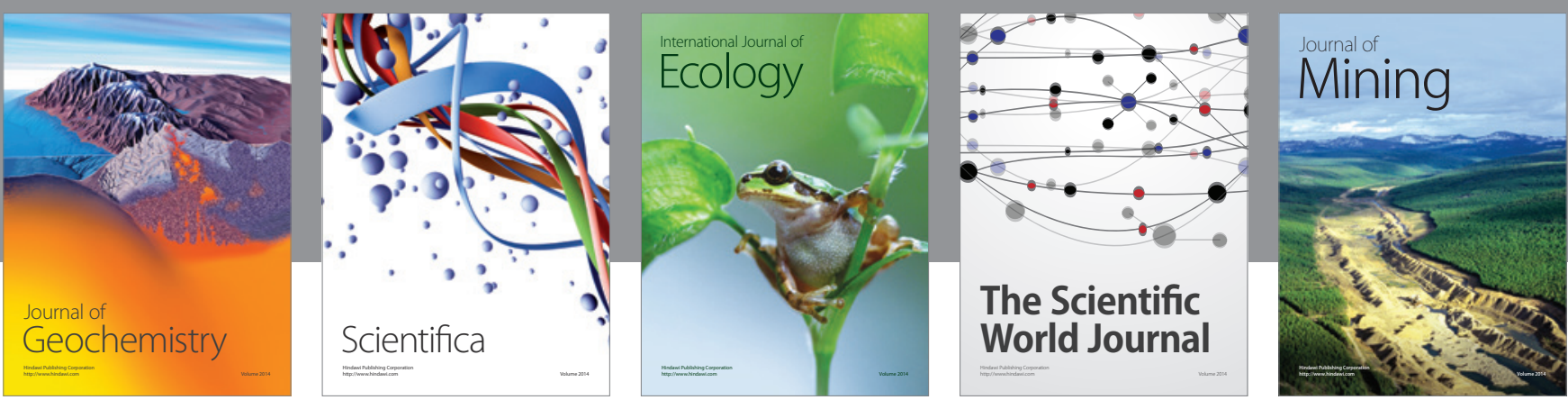

The Scientific World Journal
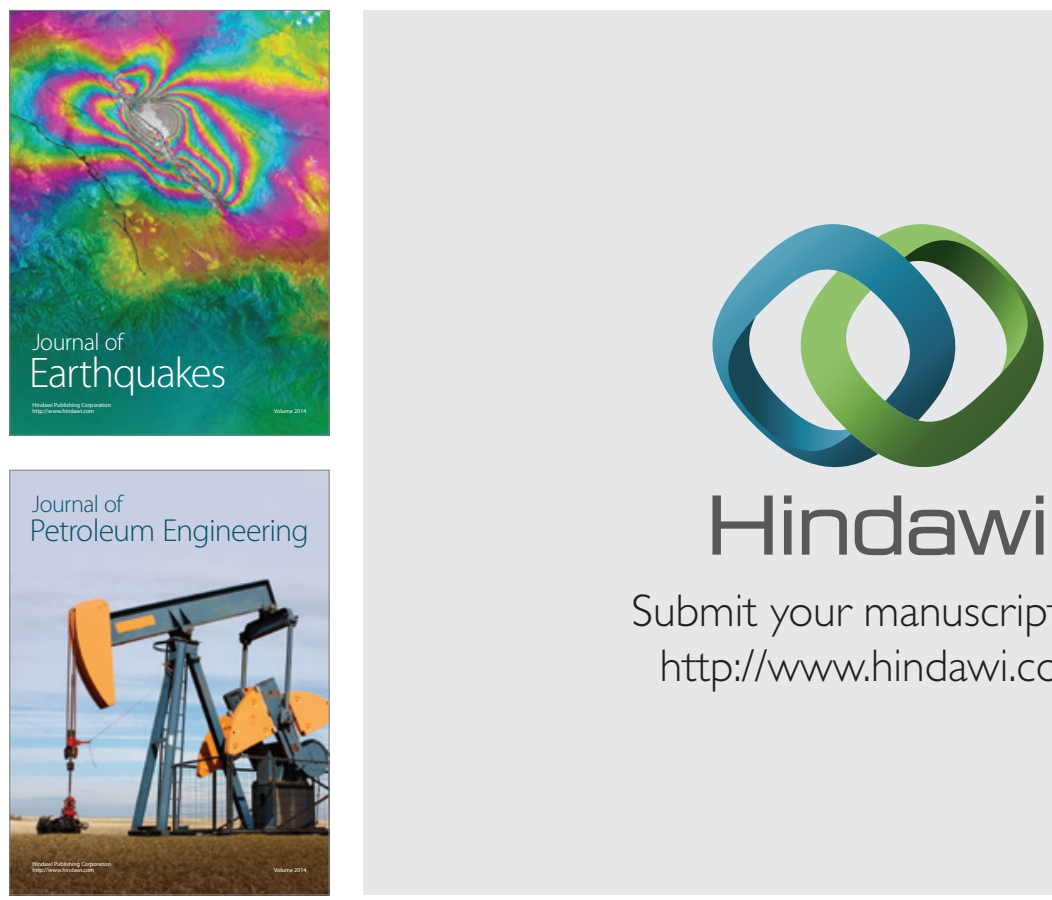

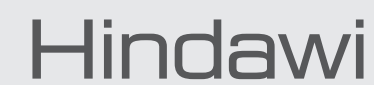

Submit your manuscripts at

http://www.hindawi.com
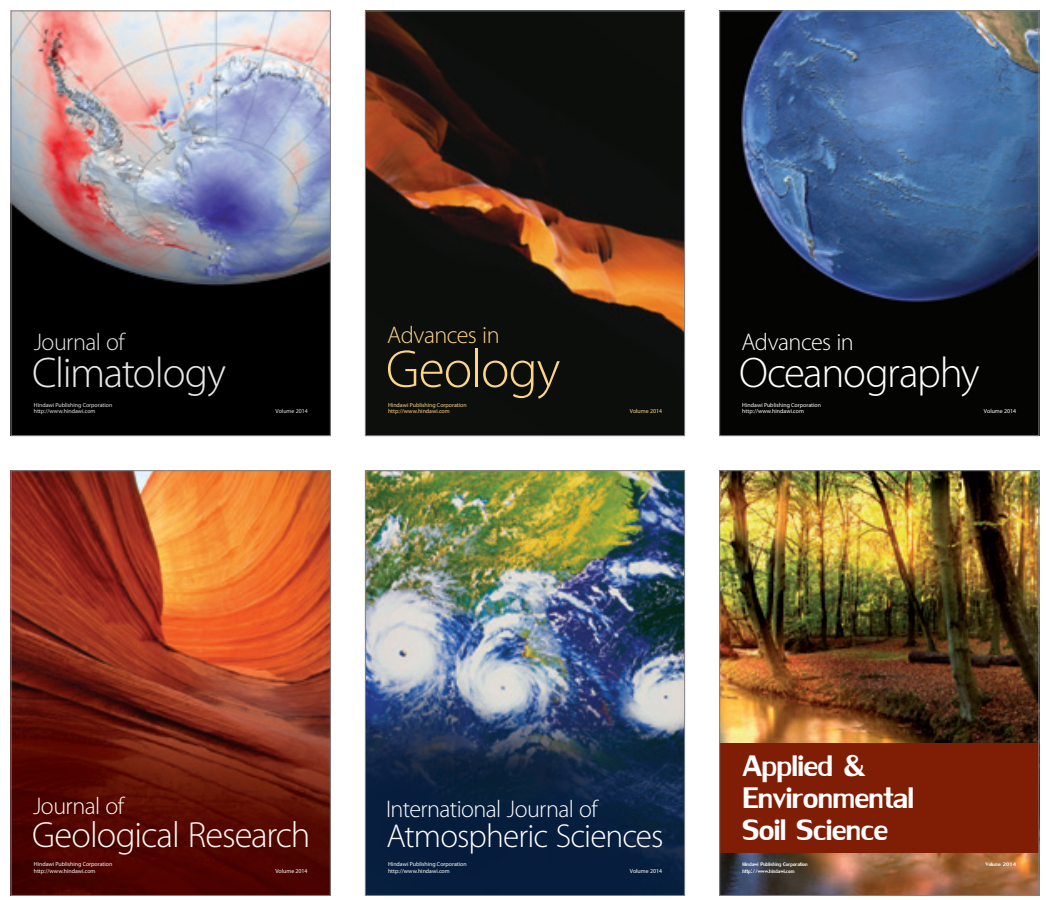
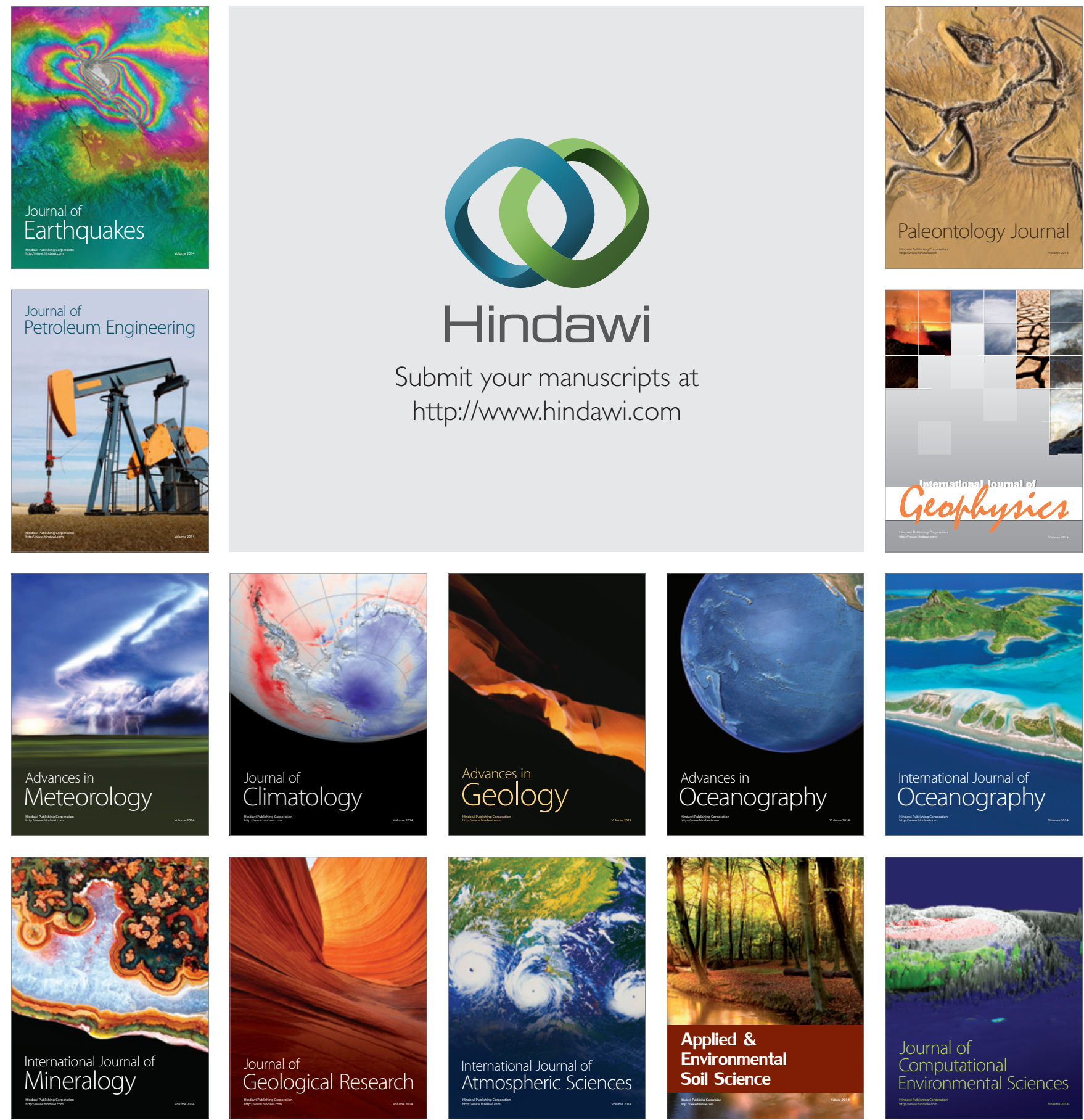